\title{
MUDANÇAS DE AÇÕES GOVERNAMENTAIS NO TOCANTE A LOGÍSTICA E INFRAESTRUTURA PARA DESENVOLVIMENTO DO COMÉRCIO EXTERIOR
}

\section{ARTIGO ORIGINAL}

COSTA, João Maurício de Jesus ${ }^{1}$

ORTUNES, Leandro ${ }^{2}$

COSTA, João Maurício de Jesus. ORTUNES, Leandro. Mudanças de ações governamentais no tocante a logística e infraestrutura para desenvolvimento do comércio exterior. Revista Científica Multidisciplinar Núcleo do Conhecimento. Ano 05, Ed. 10, Vol. 03, pp. 12-28. Outubro de 2020. ISSN: 2448-0959, Link de acesso: https://www.nucleodoconhecimento.com.br/lei/mudancas-de-acoes

\section{RESUMO}

Atualmente, existe uma defasada infraestrutura/logística no Brasil. A ineficiência neste ponto em específico não colabora para que haja um planejamento sólido quanto ao possível crescimento de um país, sem contar que vivemos nos últimos anos em uma profunda crise financeira, tornando-o incapaz de realizar melhores e maiores

${ }^{1}$ Pós-graduado no curso de Direito Penal e Direito Processual Penal da rede de ensino Luiz Flávio Gomes - LFG; MBA em Gestão de Logística Internacional pela Associação Brasileira de Comércio Exterior; Global Management pela Massachusetts Institute of Business - MIB; Pós-graduado em Direito Constitucional e Tributário pela Faculdade Metropolitana do Estado de São Paulo - FAMEESP; Bacharel em Direito pela Instituição Paraibana de Ensino Renovado - INPER.

2 Orientador. Doutorado em Ciências Sociais. Mestrado em Ciências Sociais. Especialização em Ciências da Religião. Especialização em Relações Internacionais. Graduação em Ciências Sociais. Graduação em Administração com Habilitação em Comércio Exterior. 
investimentos para a área logística. O Brasil perde bilhões de reais/dólares por conta dos custos logísticos e da ineficaz infraestrutura encontrada. De todo modo, as empresas, principalmente nos últimos anos, vêm intensificando meios de oferecer seus produtos com maior eficácia na entrega, com preço competitivo e, de qualidade superior à de seus concorrentes. Questões que envolvem infraestrutura e plano de desenvolvimento logístico de responsabilidade do governo brasileiro vão ter outra visão com a mudança de Presidente da República e, ao que se aponta, boa parte dos modais terão incidências diretas das concessões que ocorrerão, bem como os investimentos que serão aportados. Neste trabalho científico, a finalidade é identificar pontos de relevância para melhoria da infraestrutura logística do país e apontar atividades governamentais para que haja uma retomada do planejamento e investimento. Para isso, foram mapeados diversos "gargalos" e apresentadas perspectivas com a mudança da orientação governamental frente a uma nova política para o setor. $O$ fato é que a política adotada até agora não tem apresentado resultados satisfatórios e, assim sendo, novas tecnologias, infraestrutura de maior qualidade, menor burocracia, bem como, maior interação da cadeia de suprimentos podem fazer com que o Brasil reconquiste sua competitividade em face dos diversos outros países, mas até o presente momento foi possível concluir que a política apontada se mostra favorável e promissora para anos vindouros.

Palavras-chave: Infraestrutura, cadeia logística, custo Brasil, planejamento governamental.

\section{INTRODUÇÃO}

O presente trabalho científico tem por finalidade mostrar a importância da retomada do planejamento e investimento, em caráter de urgência, pelo Estado Brasileiro para ofertar o mínimo de qualidade e possibilidade de disputa comercial em face de outros países em desenvolvimentos ou já desenvolvidos.

Cristalino é, que o Estado, desde a redemocratização ocorrida em 1988, não vem se preparando para alavancar sua economia através de um eficiente ambiente logístico. Parte desta ineficiência decorre da falta de planejamento, bem como pela rede 
ineficiente de infraestrutura. Diga-se de passagem, que o Estado Brasileiro perdeu completamente sua capacidade de fazer um planejamento eficiente para longo prazo. Isso é extremamente preocupante tendo em vista, principalmente, que grandes obras que poderiam desafogar o ambiente caótico não se fazem em alguns dias ou meses, muito menos se alcançam os resultados nesse mesmo período.

O crescimento mundial de negociação no setor industrial e varejista por conta principalmente dos e-commerces apresenta que, a interligação negocial se espalhou de tal maneira que a cadeia logística tem total interferência nas escolhas para aberturas de novas empresas, instalações de empresas já solidificadas no mercado, bem como a opção por aquisição de produto/commodity de um determinado país. Atualmente uma venda realizada na china pode chegar ao Brasil em apenas alguns dias e as empresas tentam se adaptar e se preparar para esses novos mercados. Para tanto, a logística de um país pode ajudar ou prejudicar, e muito, essa negociação. A infraestrutura/logística existente pode acelerar ou não uma entrega, bem como tornar ainda mais atrativo o valor final do que venha a ser comercializado. $O$ inverso se aplica, ou seja, o Brasil perde muito quando não tem o mínimo necessário para enviar seus produtos para outros mercados consumidores de maneira eficiente e mais barata, já que estes campos são deficitários e extremamente burocráticos.

Nossas ferrovias foram sucateadas, abandonadas ou pouco utilizadas, tudo em decorrência do lobby exterior para o Brasil adotar priorizar as rodovias a partir dos anos 50. Momento oportuno para chamar a atenção de nossa total dependência deste modal (rodoviário), foi verificada na chamada "greve dos caminhoneiros" ocorrida recentemente e que paralisou o país, além de deixar um rastro de prejuízo que chegou na casa do $R \$ 3$ bilhões de reais. Nossas vias aquaviárias são exploradas abaixo da capacidade possível, além, é claro, de não ter recebido investimento suficiente para sua exploração e manutenção. Nossos portos, embora ainda ofereçam a melhor e mais eficaz saída de produtos nacionais, ao longo do tempo vem se mostrando inoperante diante das exportações requeridas e, extremamente ridículos em sua capacidade operacional. Acumulando-se durante esses últimos trinta anos, vemos um gargalo impossível de ser corrigido em curto ou médio prazo, muito embora, as 
empresas atuantes venham travando as duras penas o constante avanço nos mercados externos mesmo não tendo o ambiente regulatório com base sólida e que Ihes passem a segurança jurídica necessária para essa atuação mais robusta, tornando o ambiente exportador nacional um local para poucos se arriscarem.

Tivemos recentes tentativas de alavancar a infraestrutura nacional com lançamentos de grandes programas voltados para infraestrutura. Podemos listar, a título de exemplo, os Programas de Aceleração do Crescimento 1 e 2, o Programa de Investimento em Logística (PIL) 1 e 2 e o Crescer. Os resultados ficaram muito longe do prometido, deixando um rastro de corrupção, obras inacabadas, quando não, nem iniciadas. Obras no Brasil tem um raro talento para demora na entrega e o superfaturamento. Não é nem um pouco desproporcional informar que, por ano, o país tem prejuízo aproximado em $\mathrm{R} \$ 200$ bilhões somente com a corrupção (levando-se em consideração todas as áreas e, não somente, nas obras públicas).

Dessa forma, imperioso a montagem deste cenário logístico/estrutural do país para que sejam apresentados dados que apontem possível origem do problema, desde o modelo de ação adotada por cada governo que implementou sua impressão digital na política para o setor e as mudanças que se avizinham.

Para compor o referencial teórico, foram encontrados 28 materiais por meio do descritor controlado abandono logístico nacional and gargalo da infraestrutura brasileira e 31 trabalhos utilizando o descritor logística e infraestrutura brasileira and prejuízo causado pelo desinvestimento. A partir dos critérios de exclusão, foram selecionados 16 materiais dentre livros, artigos e dissertações. Para a coleta de dados, os critérios de inclusão foram trabalhos que estivessem na língua portuguesa, que compreendessem o período a partir do ano 2004 até março de 2019 e que estivessem disponíveis na íntegra. Já os critérios de exclusão foram artigos repetidos e aqueles que após a leitura dos resumos não fossem pertinentes ao tema. 


\section{DAS PROBLEMÁTICAS EXISTENTES}

Não tem a menor possibilidade de um país ter um crescimento econômico sólido sem que sua rede de infraestrutura seja eficiente e, ao mesmo tempo, de qualidade, atendendo assim os objetivos diversos, seja através da viabilidade do produto/commodity, fortalecendo o consumido interno, mas não somente a ela, bem como os diversos meios transportes possíveis e, também, os centros de comunicações sejam todos eles eficientes. De fato, em um país com tamanho continental como o nosso (para escoamento nacional e, principalmente, para o escoamento internacional, foco desse trabalho), sem contar que é importante que se otimizem os recursos.

Devemos nos ater que a fase de distribuição não pode receber atenção menor, pois envolve não somente a carga e descarga de diversos produtos/commodities. $\mathrm{Na}$ cadeia logística, é primordial saber utilizar o mais eficiente para ser utilizado, adequando a necessidade do cliente, mas extraindo deste ponto, o máximo de eficiência e baixo custo da operação. Essa situação se torna ainda mais complexa quando se envolve comércio exterior, em que a logística se torna ainda mais importante para ter agilidade, eficiência e preço competitivo.

Transporte rodoviário, fluvial e ferroviário para escoamento inicial, bem como o aéreo e marítimo para escoamento final, devem passar por diversas situações em que o país de origem (no caso em tela, para exportação), tem que estar alinhado oferecendo estrutura para que toda cadeia se desenvolva de maneira correta e adequada. $\mathrm{O}$ retorno é impressionante quando se tem uma cadeia logística atuando dentro da conformidade exigida. Analisar as rotas, que tem fatores independentes e determinantes, tais quais as necessidades se apresentam, o principal é a disponibilidade logística e de infraestrutura ofertada, que poderá impactar de forma profunda nos custos, torna atrativo ou não o país.

Os modais oferecidos no Brasil, em regra, apresentam diversos problemas e, com isso, necessitam de muitos investimentos, em massiva expressão no modelo de 
gestão governamental escolhido até então, pelo Estado Brasileiro para que ocorram às melhorias e possíveis adequações das deficiências identificadas.

O modal rodoviário, quando colocado em análise mais atenta, apresenta números bastantes preocupantes quando não estão nas principais rotas do país. Em sua maioria, as vias são de péssimas condições de trafegabilidade e, não possui nenhum tipo de segurança. Ora, o Brasil tem um dos maiores agronegócios do mundo, sendo extremamente exportadora, inclusive livrou o Brasil de ter um desempenho ainda pior no PIB por diversos anos, mostrando força mundial, imaginemos se tivéssemos uma logística e infraestrutura adequada para atender toda essa demanda, barateando o custo final da mercadoria/commodity nacional?

Segundo (VIANNA, 2004) as rodovias vem sofrendo por anos com os baixos investimentos por parte dos diversos governos que já se passaram, sendo que este modal transporta mais ou menos $80 \%$ (oitenta por cento) da produção nacional e, ainda sim, encontra-se em estado de conservação muito precário, sem contar os diversos trechos em que são quase inexistentes.

Já, o modal ferroviário é uma opção que deveria ter a atenção adequada tendo em vista o tamanho do Brasil, mas que necessita urgentemente realizar um projeto de interligação de suas estruturas, criando um padrão entre os Estados e operadores das vias existentes.

Os portos, como não deveria deixar de ser, necessitam de investimentos buscando uma eficaz utilização e atendendo novos parâmetros mundiais. Encontramos um ambiente ainda bastante burocrático na formatação atual, o que vem a comprometer sua expansão. O sistema de portos nacionais, na contramão do que ocorreram nos internacionais, vem perdendo continuamente capacidade operacional por já não está caminhando conforme exigências do mundo moderno quanto ao que se refere a carga e descarga. Esta situação se apresenta pelo passado exportador que carregamos, vez que o Brasil somente operava com exportações de produtos basicamente primários, não sendo realizado operações por meio de contêineres, processo este que perdurou até a década de 90 (OLIVEIRA, 2005). 


\subsection{DO MODAL RODOVIÁRIO}

O transporte por rodovia foi o escolhido como prioritário para carga e descarga no país. Como não poderia deixar de ser, por ser o modal escolhido, chegamos aos números de 63\% (sessenta e três por cento), e 770 bilhões de toneladas por quilômetro útil, movimentadas. (ILOS, 2012a).

Por conta do fomento governamental na linha de crédito para aquisição de diversos bens, incluindo caminhões, a utilização massiva do modal viário e, atrelado a este fato, possuir maior preço unitário, atrás apenas para via aérea, transforma o transporte por rodovias o causador do impacto dantesco nos custos operacionais. Não obstante o país possua vasta extensa de malha rodoviária, sendo registrada, inclusive, como uma das maiores do mundo, ainda encontra-se em defasagem face as outras nações, tendo registro de apenas 13\% (treze por cento) das rodovias devidamente pavimentadas. A título comparativo, os Estados Unidos possuem questões territoriais muito próximas ao do Brasil, possuem 4,37 milhões de km de suas malhas viárias pavimentadas, sendo que aqui temos apenas 214 mil km. Já na Índia que possui área menor que a brasileira em ao menos 3 (três) vezes, possuindo, aproximadamente, 1,4 milhão de km pavimentado (BRASIL, 2010).

A somatória de todos estes problemas no Brasil, quais sejam: material asfáltico de qualidade duvidoso, conservação precária, construção com itens de baixa qualidade em detrimento do lucro e, caminhões acima do peso permitido para trafegabilidade são incidentes que produzem efeitos diretos nas estradas brasileiras. Estudos revelam que apenas $1 \%$ (um por cento), de carga acima do limite em um eixo pode gerar um desgaste de 4,32\% (quatro, trinta e dois por cento) no pavimento. Se tivermos uma sobrecarga de $5 \%$ (cinco por cento), uma rodovia que era para durar 10 (dez) anos, pode resistir apenas 8,1 anos. Já se exceder 20\% (vinte por cento), essa vida útil será algo em torno de 4,5 anos (REIS, 2011a).

Por óbvio, as péssimas estradas reflete diretamente no custo elevado por este modal. A má condição da via pode ocasionar em redução de velocidade, por correlação, a quantidade de viagens possíveis de serem realizadas por dia também sofre reduções 
e, consequentemente, eleva-se o custo/viagem. Devemos levar em consideração também que, com rodovia em má condição de trafego, maior incidirá o desgastes do caminhão, o que terá impacto direto no custo da operação (REIS, 2011b). Em pesquisa realizada pela CNT (2010), a frota nacional poderia ter seu custo reduzido em aproximadamente $25 \%$ (vinte e cinco por cento), se as rodovias do país possuíssem manutenção adequada.

\subsection{DO MODAL AÉREO}

No modal aéreo temos uma completa falta de estrutura adequada para se ter uma logística de primeiro mundo. Sua conhecida burocracia torna lento todo processo de desembaraço dos diversos itens, podendo chegar até 1 (uma) semana para isso ocorrer. No mercado internacional, as mercadorias denominadas de primeira classe, em regra, seguem este tipo de transporte. No país operamos com menos de 1\% (um por cento) do envio de cargas para o exterior através da via aérea. Estas mercadorias somam mais de $10 \%$ (dez por cento), do total. Pelas vias aéreas normalmente chegam produtos que possuem valor agregado significativo e/ou que necessitam entregas rápidas.

O transporte por avião se torna mais recomendável para envio de produtos eletrônicos diversos, tendo em vista a necessidade de entrega rápida já que em breve espaço de tempo, estes mesmos aparelhos já serão substituídos por outros de qualidade superior (KEEDI, 2000). Nos aeroportos brasileiros, vemos nossa vantagem competitiva se perder, dentre outras situações, por conta da excessiva burocracia. A Federação das Indústrias do Rio de Janeiro, em 2013, realizou uma pesquisa que apontava o seguinte: Nos 5 (cinco) maiores aeroportos de carga, o tempo médio para liberação de mercadorias é de 175 (cento e setenta e cinco) horas. Se formos analisarmos em confronto com aeroportos espalhados pelo mundo, encontramos que em Londres o tempo médio é de 8 (oito) horas; nos Estados Unidos, leva-se em média 6 (seis) horas, e, na China, "demora" algo em torno de 4 (quatro) horas. O setor que mais sofre com essa demora é justamente o de necessidade ímpar, o farmacêutico. A título comparativo, se uma carga possui valor de $\mathrm{R} \$ 35$ milhões, no aeroporto do 
Rio de Janeiro terá um custo de $\mathrm{R} \$ 287$ mil reais. Já em Cingapura custaria algo próximo a 40 vezes menos (FIRJAN, 2013).

\subsection{DO MODAL FERROVIÁRIO}

Esse tipo de transporte poderia ser melhor aproveitado tendo em vista nossa imensidão geográfica. Claro, foi sucateado, abandonado, entretanto mesmo com diversos problemas, ainda sim são passíveis de melhorias. Não podemos apontar um problema apenas como o gargalo, mas é reconhecida a necessidade de intervenções urgentes. Temos, por exemplo, gargalos físicos, que ocasionam diminuição de velocidade, restringindo o uso eficaz do transporte por este modal, elevam os custos. Foi identificado também que, em diversos trechos, existem passagens que por vezes acabam reduzindo drasticamente a velocidade e torna complexa a circulação em áreas povoadas, o que por consequência torna elevado o risco de acidente. Segundo pesquisa realizada pela CNT, aponta sendo realizado a intervenção correta, mesmo que inicialmente acabe significando o aporte financeiro por parte do Estado ou da iniciativa privada, economicamente ela se tornará muito interessante, já que os custos destas intervenções somem $R \$ 7,1$ bilhões, ainda sim, gerará benefícios que podem chegam a $\mathrm{R} \$ 19,2$ bilhões.

Os resultados desta mesma pesquisa, uma boa parte desses gargalos existentes são oriundos da forma como as ferrovias no Brasil foram idealizadas. Podemos trazer a título de exemplo a inexistência de especificações padrões para todo o país. A falta de uniformidade técnica das vias férreas e/ou bitolas, refletindo assim numa falta de conexão entre as malhas e, por óbvio gerando custo extra advindo deste transbordo necessário, elevando o tempo operacional para transbordo desta carga. Fatores como estes acabam por vez inibindo os ganhos oriundos das economias possíveis no uso do modal ferroviário, bem como o desenvolvimento e das atividades econômicas geradas pelo transporte (CNT FERROVIAS, 2011).

Após investimentos públicos programados ao longo dos anos pressupõe ter promovido a expansão da via ferroviária nacional, como por exemplo, a construção da linha Norte-Sul e a linha de Integração Oeste-Leste. O que foi identificado na prática 
era o inverso do esperado. Drasticamente ocorreu a redução no volume de recurso destinado ao setor, causando assim praticamente a paralisação das grandes e necessárias obras de infraestrutura ferroviária (CNT FERROVIAS, 2011).

\subsection{DO MODAL MARÍTIMO (PORTOS)}

Os problemas portuários são vários. Destacamos o excesso burocrático de documentos - muito embora com o novo sistema tecnológico tenha ajudado a diminuir esse excesso de informação -, as exigências legais por parte das diversas agências reguladoras, atrelado ao longo tempo de espera para ocorrer movimentação de carga devido, boa parte, em nome da verificação de documentos pertinentes nos portos nacionais, tornaram, os apontados, como maiores responsáveis pelo gargalo no setor em tela. Tais resultados foram apontados através de pesquisa feita pelo Instituto (ILOS, 2012b). Ademais, conforme já deveras conhecidas as enormes filas de espera para descarregar nos portos, não contribuem em nada. As estruturas portuárias são precárias para acolhimentos dos milhares de motoristas que, por conta da falta de capacidade operacional, tem que esperar por horas ou, até mesmo, dias para realizar o procedimento de embarque e desembarque dos itens nos pátios, tornando o custo desta operação algo a ser apreciado no custo fim.

Em decorrência do inchaço nos portos nacionais, o acesso pelas vias terrestres são aspectos relevantes em toda essa cadeia logística. A pesquisa (ILOS 2012b) registra ser um problema crônico e conhecido das autoridades responsáveis. As insuficientes vias, próximas às cidades, tornam o tráfego complicado, gerando engarrafamentos $\mathrm{e}$, as ineficazes ou inexistentes vias exclusivas acabam gerando uma competição entre os modais, quando, em verdade eles seriam complementares uma com as outras, acabando assim por se tornar uma das maiores reclamações (ILOS 2012b).

Se não bastassem todos os problemas já elencados acima, o custo do manuseio de carga no pátio, análise de documentação, deslocamento de carga para o navio, entre outros também são pontos observados. Dessa forma, inegável que é custo para o usuário exportar via portos brasileiros, encarecendo o preço final do produto/mercadoria, perdendo dessa forma, o produto nacional a competitividade face 
ao oferecido por outros mercados. Após romper todos estes obstáculos, outros se apresentam. Como não poderia deixar de ser, falta capacidade para realizar armazenagem dos diversos produtos nos portos nacionais e este é só mais uma deficiência que deve ser sanado a curto e médio prazo.

Sobre os portos, ainda poderíamos citar alta taxa de demurrage; sobre a demora na análise documental, trâmites com as agências reguladoras atuantes nos portos: Receita Federal, Anvisa, Ibama e Polícia Federal, embora por conta do sistema unificado isso tenha tido uma melhora significativa -, bem como o alto tempo encontrado atualmente para atracação das embarcações.

\section{DO DESENVOLVIMENTO PARA O SETOR DE INFRAESTRUTURA/ LOGÍSTICA PARA O COMÉRCIO EXTERIOR NOS ÚLTIMOS ANOS}

Inegável que no período compreendido entre 2003 à 2013 os investimentos em logística e na infraestrutura do país triplicaram, em termos reais, alcançando cerca de $\mathrm{R} \$ 200$ bilhões de reais, e, deveria ter ocorrido em decorrência da economia exigindo ampliação ainda maior dos investimentos em logística, o que veio a ocorrer, entretanto os investimentos maciços do governo esbarraram, dentre outras, na problemática chamada corrupção. Ou seja, investia-se muito, mas investia-se mal e, como era de se esperar, o gargalo estrutural logístico cobrou seu preço nos anos posteriores.

O ano de 2004 foi muito importante para balança comercial nacional: os números registrados pelas exportações chegaram ao patamar de US $\$ 94$ bilhões e com isso os diversos setores envolvidos trouxeram à baila toda problemática existente e mostrar que os números poderiam ser maiores ainda. Foi possível identificar formações de filas veículos para descarregar e carregar, congestionamentos nos portos nacionais, navios com espera acima da média tolerável para atracar (SAFATLE e RIBAMAR, 2004), estradas em estado de conservações precárias que, por consequência, torna o tráfego dos veículos cada vez mais lento (GAZETA MERCANTIL, 2004) e invasões e favelização das vias férreas. 
Mesmo sendo possível observar tais fatores sem maiores dificuldades, a atuação governamental foi pífia e em total desconformidade com a problemática que se apresentava. Foi verificado que com a ineficiência logística não há outra resposta que não a afetação da competitividade brasileira e, o fato de não sofrer a intervenção devida por um longo período, cada vez mais se agrava o quadro panorâmico sobre o tema.

\subsection{DO DESENVOLVIMENTO PARA O SETOR DE INFRAESTRUTURA / LOGÍSTICA PARA O COMÉRCIO EXTERIOR PREVISTO PELO ATUAL GOVERNO}

No programa de governo do atual presidente da República Federativa do Brasil, foi apresentado diversos projetos para a melhora e avanço no tocante ao setor de logística e infraestrutura, o que cominará, se implantado em sua totalidade, com um rápido escoamento das commodities e produtos nacionais para o exterior. O governo prepara um novo Plano Nacional de Logística - PNL, que entrou em fase de consulta pública.

Por óbvio, sabemos que o viés econômico que um determinado governo é aderente, impacta diretamente e indiretamente no desenvolvimento de sua infraestrutura interna e na sua rede de logística. Não se procura aqui fazer juízo de valor acerca de qual lado se está, mas o importante é entender se quando há uma concentração maior e presença do Estado, se este consegue de fato ofertar essa qualidade desejada. Caso não, o Estado menor permite que atores diversos com interesse na expansão negocial opere e explore. Assim sendo, optando pela segunda escolha cabe a iniciativa privada realizar o aporte financeiro, se comprometendo com a qualidade do serviço prestado e retirando dele seu lucro.

O Brasil desde a época da redemocratização nunca teve um governo de direta, sempre caminhando ao longo desses anos com governo de esquerda alinhada ao centro e, por isso, devemos agora observar como serão os próximos anos do país com um governo de alinhamento diverso. Haverá evolução, ganhos ou melhorias? Só 
saberemos mais adiante as respostas suscitadas. Para tanto, vejamos o que se tem até a presente data.

\subsubsection{FERROVIÁRIA}

Podemos, por exemplo, apontar a criação do Ferrogrão, que escoará mais de 70 \% (setenta por cento) da safra oriunda do Mato Grosso. Essa ferrovia tem o condão de interligar o Estado Mato Grosso com o do Pará. Concretizando tal projeto a safra poderá saltar de 63,18 milhões de toneladas (2018), para mais de 100 milhões de toneladas em 10 (dez) anos, de acordo com projeções do Instituto Mato-Grossense de Estudos Agrícolas (Imea).

Somente na concessão da ferrovia Norte-Sul (FNS), o governo arrecadou $R$ \$ 2.719.530.000,00 (dois bilhões, setecentos e dezenove milhões, quinhentos e trinta mil reais), sendo que os investimentos mínimos para esta ferrovia deverão ser de $R \$$ 2.8 bilhões de reais no prazo de 30 (trinta) anos.

\subsubsection{PORTOS}

Não obstante a incapacidade do Estado de gerir de maneira eficiente portos espalhados pelo Brasil, está em curso o projeto de desestatização com o arrendamento de 16 (dezesseis) novas áreas portuárias, incluindo 3 terminais do Porto de Cabedelo (Pb). Somente em 10 (dez) terminais portuários os investimentos que deverão ser realizados beiram os $\mathrm{R} \$ 430$ milhões de reais nos próximos 25 (vinte e cinco) anos.

\subsubsection{AEROPORTOS}

Doze novos leilões (concessões), de aeroportos foram realizados, gerando uma receita para o país em algo em torno de $R \$ 4,2$ bilhões de reais ao longo de 30 (trinta) anos. Ademais, os investimentos para o setor envolvem cifras na casa dos $R \$ 8.8$ bilhões de reais, durante o período de concessões. A previsão é de que até 2022 
outros 44 (quarenta e quatro) aeroportos serão concedidos a iniciativa privada, gerando investimento, receita para a União, geração de emprego e renda.

Importante salientar que o Senado Federal aprovou o acordo de "céus abertos" entre Brasil e EUA, o que poderá aumentar de maneira significativa a melhora para quem utiliza diversos serviços advindos deste modal.

\subsubsection{RODOVIÁRIA}

A atuação nos primeiros 100 (cem dias) dias do atual governo aponta para entregas de obras rodoviárias que até então encontravam-se paralisadas, como por exemplo a BR-170 (Boa Vista/RR), restauração da BR-401, bem com quase 90\% (noventa por cento) da extensão coberta por contratos de manutenção e cerca de 96\% (noventa e seis por cento) em condições boas ou regular. A BR-163 (Pa), principal rota para saída de safra de grãos também é pauta da força tarefa para escoar com mais rapidez os produtos da região Norte do país.

A rodovia de integração do sul (Br's-101/290/386/448/RS), com investimentos programados de $\mathrm{R} \$ 7,8$ bilhões de reais, também já está em andamento, bem como as obras de duplicação e melhorias da BR-280 e BR-470 que tem início programado para o primeiro semestre do ano de 2019. O mesmo ocorre nas obras nas rodovias de Tocantins. Ou seja, estamos verificando forte investimento/concessão nos setores que mais travam um comércio exterior pujante.

Como dito acima, não é comum traçar um paralelo sobre algo que já está consolidado com dados técnicos e conhecidos frente ao que ainda é desconhecido em termos de resultados práticos. Fato é que estamos verificando uma mudança radical na política econômica, de investimento, de alinhamento geopolítico, de atuação do Estado Brasileiro, deixando de ser o ator principal para conceder a iniciativa privada esse papel. 
O que podemos de fato registrar é que o Brasil passará por enorme atividade de desestatização, o que anteriormente era combatido. Mas, o que vem a ser "desestatização"?

A Lei 9.491 de 1997, no art. º $§ 1^{\circ}$, atribui ao vocábulo "desestatização" o seguinte sentido:

$\S 1$ ํ. Considera-se desestatização:

a) $(\ldots)$;

b) a transferência, para a iniciativa privada, da execução de serviços públicos explorados pela União, diretamente ou através de entidades controladas, bem como daqueles de sua responsabilidade.

c) (...).

O artigo $2^{\circ}$ da mesma lei diz que podem ser objeto de desestatização:

Art. $2^{\circ}$. Poderão ser objeto de desestatização, nos termos desta Lei:

I - (...);

II - (..);

III - serviços públicos objeto de concessão, permissão ou autorização;

IV - (...);

$V-(\ldots)$.

Assim sendo, a política do atual governo tende a ser de um Estado menos atuante diretamente neste setor, vindo a fazer apenas investimentos pontuais e deixando para que a iniciativa privada invista e explore em detrimento de uma "qualidade" na prestação de serviço mediante remuneração. De todo modo, o país não tinha capacidade econômico-financeira de realizar os investimentos necessários obtendo de outra banda um retorno efetivo, com baixo risco de abandono de obra, rapidez na entrega e baixa ocorrência de corrupção. Para isso, a iniciativa privada se mostrava mais adequado a explorar e ofertar serviço de qualidade do que o próprio Estado, 
restando a este, investir em outras demandas não abarcadas pela iniciativa privada para complementar e desafogar nosso gargalo logístico/estrutural.

Dito isso, teremos que aguardar a mudança na forma de se investir na infraestrutura do país para extrair os resultados e apontar se ao menos foi vantajoso para o comércio exterior essa abertura para a exploração pela iniciativa privada. De antemão, os investimentos se mostram mais interessantes que a capacidade do Estado em fornecer e o fato das empresas atuantes necessitarem de retorno imediato, fazem com que busquem a eficiência na prestação de serviço.

Nosso setor é tão deplorável que países como: Vietnã, Tailândia, Turquia, Filipinas, índia, Sérvia, El Salvador e outros, tenham uma infraestrutura logística melhor que a nossa. Ou seja, precisamos urgentemente repensar nosso modelo de gestão política praticado até aqui para mudar o panorama do país e ofertar novas possibilidades para viabilizar o sonhado crescimento econômico para o país e para aqueles que apostam em seus negócios.

\section{CONSIDERAÇÕES FINAIS}

Sem sobra de dúvida a logística nacional é o maior dos problemas que impedem de alavancar diversos setores, entretanto, todos esses entraves largamente reconhecidos pelas autoridades responsáveis, o Brasil continua sendo produtor de enorme capacidade, estando, por exemplo, figurando entre os principais exportadores no que tange aos produtos agrícolas.

Até o presente momento os investimentos em infraestrutura e na cadeia logística nacional não acompanhou e não foi bem gerido face o aumento da produção, ocasionando os problemas logísticos. Nosso investimento, se tomarmos em comparação com países diversos foi irrisório, logo, retrata nosso quadro atual, aliado ao já escasso recurso para este propósito e, soma-se ainda, os descalabros oriundos da corrupção existente e alarmante no país. 
Com todo o Custo Brasil envolvido para efetivar a saída da produção nacional para o exterior, torna, como dito anteriormente, os preços dos produtos nacionais serem elevados, tornando-os não atrativos no comércio mundial.

O Brasil é, e continuará sendo se nada for feito, refém do modal terrestre, que também possui diversos problemas, além de ser um modal caro em comparação com outros tipos possíveis de serem utilizados, como o ferroviário, que é, e poderá ser muito mais utilizado, para saída de produtos/commodities para vários países.

De uma maneira geral temos como apontar que, resolver os problemas estruturais da nossa cadeia logística só ocorrerá com investimentos consideráveis, mas que infelizmente o Ente Público, no atual cenário econômico não tem como fazer, mesmo assim, este deverá ofertar maior atenção para que soluções sejam apontadas e efetivadas, muito embora, já se vislumbra através das concessões ocorridas um norte para desafogar e minimizar os problemas para com o setor de infraestrutura e logística. O crescimento e modernização das diversas malhas (dos diversos modais) que atendem o país chegarão através de ambiente mais atrativo para a inciativa privada, passando estes a realizarem investimentos e, por óbvio, explorem, cabendo ao governo efetuar planejamento e fiscalização.

Posto isto, as mudanças sazonais de políticas públicas defendidas por diversos estilos de governos serão sempre bem-vindos para que com isso alavanque, cada um ao seu modo, os setores estruturantes de uma cadeia de logística que faça com que as exportações sejam maiores, advindo assim, de menor custo final fazendo frente para produtos internacionais, abrindo ainda mais o mercado nacional para o mundo todo.

\section{REFERÊNCIAS}

CNT. Pesquisa CNT de Rodovias 2010: relatório gerencial. Brasília, 2010.

. Pesquisa CNT de Rodovias 2011: relatório gerencial. Brasília, 2011.

FIRJAN. Brasil mais competitivo: ganhos com o funcionamento 24 horas dos órgãos anuentes nos aeroportos. Rio de Janeiro. 2013. 
GUIA DE LOGÍSTICA. EADI - Estação Aduaneira Interior. Disponível em: http://www.guiadelogistica.com.br. Acesso em: 1ํ de abril, 2019.

Jusbrasil. Disponível em: https://jus.com.br/artigos/12228/o-processo-deprivatizacao-e-desestatizacao-do-estado-brasileiro. Acesso em: 22 de março, 2019.

LOGÍSTICA VIRA BARREIRA PARA EXPORTAÇÕES. Relatório Agronegócio Desafios. Gazeta Mercantil, Rio de Janeiro, 20 de maio, 2004.

MINISTÉRIO DA INFRAESTRUTURA. Disponível em: http://infraestrutura.gov.br/. Acesso em: 22 de março, 2019.

RECEITA FEDERAL. Portos secos. Disponível em: http://www.receita.fazenda.gov.br. Acesso em: 13 de janeiro, 2019.

SAFATLE, C; RIBAMAR, O. Empresas pagam por deficiência de portos. Valor Econômico, Rio de Janeiro, 14 de maio, 2004.

TORRES, C.L. Ineficiência logística afeta competitividade brasileira. Valor Econômico, Rio de Janeiro, 16 de julho, 2004a.

TORRES, C.L. Recursos para contornar gargalos nas ferrovias. Valor Econômico, Rio de Janeiro, 16 de julho, 2004b.

Enviado: Fevereiro, 2020.

Aprovado: Outubro, 2020. 